\title{
Path Coefficient Analysis using Rils of Oryza nivara in Swarna Background
}

\author{
N. P. S. De Silva ${ }^{1,2,3}$, V. G. Shankar ${ }^{1 *}$, D. Balakrishnan ${ }^{2}$, B. Kavitha ${ }^{2}$, Y. V. Rao ${ }^{2}$, \\ P. Prashanthi ${ }^{2}$, N. Sarla ${ }^{2}$, SNCVL. Pushpavalli ${ }^{1}$ and D. Srinivasa Chary ${ }^{1}$ \\ ${ }^{1}$ Jayashankar Telangana State Agricultural University, Hyderabad, India \\ ${ }^{2}$ ICAR Indian Institute of Rice Research, Hyderabad, India \\ ${ }^{3}$ Regional Rice Research \& Development Centre, Bombuwela, Kalutara, Sri Lanka
}

*Corresponding author

\section{A B S T R A C T}

Keywords

Rils of Oryza

nivara, Path

Coefficient

Analysis

Article Info

Accepted:

12 January 2021

Available Online:

10 Fehruarv 2071
RILS derived from a cross between Swarnax 166s (Advanced BIL of Swarna x O. nivara) were field evaluated in Rabi 2017-18, Rabi2018-19 and Kharif2019 considering the importance of yield related traits in selection for improvement of grain yield. The $\mathrm{F}_{5}, \mathrm{~F}_{6}$ and $\mathrm{F}_{7}$ generations of the RILs were evaluated as three row families in RCB design with two replicates using Swarna and 166s as checks at research farm, IIRR, Hyderabad, India under irrigated conditions. The observations were recorded for the traits plant height, total number of tillers per plant, productive tillers per plant, biomass weight per plant, 1000grain weight and single plant grain yield for which path coefficient analysis was carried out. Analysis of variance revealed that the genotypes were significantly different for the yield and other traits studied during three seasons, indicating the presence of high genotypic variability among the genotypes. Path coefficient analysis revealed that productive tiller number per plant exerted the highest positive direct effect on single plant grain yield among the traits studied. This was followed by biomass weight per plant and plant height at both phenotypic and genotypic levels indicating that selection for these traits would help to overall improvement of the grain yield in rice. Total tiller number per plant at both phenotypic and genotypic levels and 1000-grain weight at genotypic level showed negative direct effect with single plant grain yield.

\section{Introduction}

Rice (Oryza sativa L.) is possibly the oldest domesticated grain ( 10,000 years), is grown all over the world (Purugganan, 2014)and one of the world's most valuable and important food crop, cultivated in more than 100 countries and providing nutritional and economic benefits for more than half of the world population (Calingacion et al., 2014;
Roy and Shil, 2020). Ninety per cent of the world's production and consumption of rice is in Asia (FAO, 2016). Majority of the rice produced is used for direct human consumption. Rice belongs to the genus Oryza and has two cultivated species Oryza sativa and Oryza glaberrima and 22 wild species (Brar and Singh 2011; Shakiba and Eizenga 2014). 
Rice yield needs to be continuously improved to fulfill the future demands of increasing population. Improvement of rice yield is the most challenging part in breeding programmes because the yield is the most variable and complex trait influenced by various environmental and genetic factors (Pimsaen et al., 2010; Sreedhar et al., 2011; Christopher and Sangodoyin, 2011). The yield level in the released varieties has plateaued due to the narrow genetic base in the parental lines used in breeding programs. Widening the genetic base by hybridization and prebreeding is necessary to overcome the yield barrier (Roy and Shil, 2020). One of the alternatives for increasing agriculture production is to identify the genes lost or weakened during the domestication process and use them in subsequent targeted breeding programmes (Shakiba and Eizenga, 2014).

Wild species of genus Oryza, with tremendous variability, contains numerous valuable genes for improvement of several traits in cultivated rice. In India, Dhanarasi and Jarava are two rice varieties released for increased yield and they were derived from crosses with $O$. rufipogon (Ram et al., 2007, 2010). DRRDhan 40, a medium duration rice variety (BIL derived from Swarna $\times O$. nivaraIRGC81848) was released for Maharashtra, West Bengal and Tamil Nadu states of India (Haritha et al., 2016).

As a complex quantitative character, grain yield does not exist in isolation and as a result of an association with other traits form a complex relationship that ultimately affects the yield. Relative contribution of each component trait towards yield and their interrelationship is explained through path analysis. By path coefficient analysis, the correlation coefficient of various traits can be partitioned into direct and indirect effects, and this helps to assess the nature of the relationship and for effective selection for high yield. The present investigation was undertaken to screen and detect the direct and indirect effects of yield related traits on rice genotypes derived from a cross between Swarna and 166s.

\section{Materials and Methods}

Present investigation consisted of 151RILs of a cross between Oryza sativa L. cv. Swarna with 166s.Swarna, is a low-land high yielding, indica rice variety while 166s is an advanced backcross introgression line derived from a cross between Swarna and Oryza nivara by Indian Institute of Rice Research (IIRR), Hyderabad. The $\mathrm{F}_{5}, \mathrm{~F}_{6}$ and $\mathrm{F}_{7}$ generations of the RILs were planted in the research field at IIRR during Rabi 2017/18, Rabi2018/19 and Kharif2019 at irrigated field condition. One month old seedlings were transplanted in the field at a spacing of $20 \mathrm{~cm}$ $\mathrm{x} 15 \mathrm{~cm}$, as three row families in all three seasons. One row consisted with ten plants and for a replication there were thirty plants. A randomized complete block design was followed with two replications and Swarna and 166s were used as check varieties. All the recommended package of practices were adopted to raise a good crop and observations were recorded on plant height, number of total tillers per plant, number of productive tillers per plant, 1000-grain weight, biomass weight per plant and single plant grain yield. The direct and indirect effects of the component traits on yield were estimated using path coefficient analysis suggested by Wright (1921) and Dewey and Lu (1959). Direct and indirect effects at genotypic and phenotypic levels were estimated based on environment wise data and pooled data from three seasons for 153 lines.

\section{Results and Discussion}

Crop yield is the final product of the interaction of a number of interrelated 
attributes of yield and component traits. Therefore the efficiency of a selection programme for yield is mainly based on the direction and magnitude of associated traits. The study of path correlation between different traits may help the plant breeder to know how the improvement of one trait will change the expression of other traits simultaneously. Analysis of variance (Table1.) along with path andcorrelation coefficient analyses were performed for yield and related traits for all the three seasons for 153 genotypes and results of environment wise Rabi 2017/18 (Table2.), Rabi 18/19 (Table3.), Kharif 2019 (Table 4) and pooled phenotypic and genotypic path correlations (Table5.) were discussed and presented in tables.
Since the correlation studies alone are not sufficient to make the association analysis very clear, assessment of real contribution of individual character towards the grain yield per plant become essential. Path coefficient provides a clear and more realistic picture of a complex situation that exists at correlation level. It allows separation of the direct effect and their indirect effects through different attributes by partitioning the correlations (Wright, 1921). Based on the data recorded on the genotypes across three seasons in the present investigation, the pooled phenotypic and genotypic path correlations were estimated to determine direct and indirect effects of single plant grain yield and yield contributing characters.

Table.1 Analysis of variance for single plant grain yield and yield contributing traits in Swarna x 166s RILs

\begin{tabular}{|l|l|}
\hline Trait & Mean sum of square \\
\hline Plant height & $67.724 * *$ \\
\hline Total tiller number per plant & $8.192 * *$ \\
\hline Productive tiller number per plant & $7.404 * *$ \\
\hline 1000-grain weight & $6.22 * *$ \\
\hline Biomass per plant & $34.146^{* *}$ \\
\hline$* *$ significant at p=0.01 & \\
\hline
\end{tabular}

Table.2 Phenotypic and genotypic path path coefficients of single plant grain yield and yield contributing traits in Swarna x 166s RILsin Rabi 2017/18

\begin{tabular}{|l|l|l|l|l|l|l|l|}
\hline Trait & P/G & PH & TN & PTN & TGW & BM & $\begin{array}{l}\text { Correlation } \\
\text { with SPY }\end{array}$ \\
\hline PH & P & $\mathbf{0 . 1 2 2}$ & 0.018 & -0.033 & -0.010 & -0.001 & 0.096 \\
\hline & G & $\mathbf{0 . 1 8 1}$ & 0.143 & -0.203 & -0.014 & -0.004 & 0.103 \\
\hline TN & P & -0.011 & $\mathbf{- 0 . 1 9 6}$ & 0.305 & 0.011 & 0.005 & $0.115^{*}$ \\
\hline & G & -0.034 & $\mathbf{- 0 . 7 6 5}$ & 0.917 & 0.018 & 0.007 & $0.143^{*}$ \\
\hline PTN & P & -0.013 & -0.194 & $\mathbf{0 . 3 0 8}$ & 0.012 & 0.005 & $0.118^{*}$ \\
\hline & G & -0.040 & -0.759 & $\mathbf{0 . 9 2 4}$ & 0.017 & 0.007 & $0.149^{* *}$ \\
\hline TGW & $\mathbf{P}$ & 0.014 & 0.026 & -0.042 & $\mathbf{- 0 . 0 8 6}$ & 0.002 & -0.086 \\
\hline & G & 0.022 & 0.127 & -0.139 & $\mathbf{- 0 . 1 1 0}$ & 0.001 & 0.099 \\
\hline BM & P & -0.001 & -0.009 & 0.016 & -0.002 & $\mathbf{0 . 0 9 9}$ & 0.102 \\
\hline & G & -0.010 & -0.067 & 0.085 & -0.002 & $\mathbf{0 . 0 7 5}$ & 0.081 \\
\hline
\end{tabular}

PH-Plant height, TN- Total tiller number/plant, PTN- Productive tiller number/plant, TGW- 1000-grain weight, BM- Biomass weight/plant, SPY- Single plant grain yield P-Phenotypic level, G-Genotypic level 
Table.3 Phenotypic and genotypic path path coefficients of single plant grain yield and yield contributing traits in Swarna x 166s RILsin Rabi 2018/19

\begin{tabular}{|l|c|c|c|c|c|c|c|}
\hline Trait & P/G & PH & TN & PTN & TGW & BM & $\begin{array}{c}\text { Correlation } \\
\text { with SPY }\end{array}$ \\
\hline PH & P & $\mathbf{0 . 0 5 1}$ & 0.025 & -0.001 & 0.004 & 0.276 & $0.355^{* *}$ \\
\hline & $\mathbf{G}$ & $\mathbf{- 0 . 0 6 3}$ & 0.759 & -0.582 & 0.001 & 0.305 & $0.420^{* *}$ \\
\hline TN & $\mathbf{P}$ & -0.004 & $\mathbf{- 0 . 3 5 6}$ & 0.531 & -0.005 & 0.274 & $0.441^{* *}$ \\
\hline & $\mathbf{G}$ & 0.019 & $\mathbf{- 2 . 5 1 2}$ & 2.572 & -0.037 & 0.151 & $0.194^{* *}$ \\
\hline PTN & $\mathbf{P}$ & 0.000 & -0.341 & $\mathbf{0 . 5 5 4}$ & -0.006 & 0.299 & $0.505^{* *}$ \\
\hline & $\mathbf{G}$ & 0.014 & -2.473 & $\mathbf{2 . 6 1 2}$ & -0.045 & 0.197 & $0.306^{* *}$ \\
\hline TGW & $\mathbf{P}$ & 0.001 & 0.012 & -0.023 & $\mathbf{0 . 1 5 2}$ & -0.029 & $0.114^{*}$ \\
\hline & $\mathbf{G}$ & 0.000 & 0.326 & -0.414 & $\mathbf{0 . 2 8 4}$ & -0.033 & $0.163^{* *}$ \\
\hline BM & $\mathbf{P}$ & 0.025 & -0.176 & 0.298 & -0.008 & $\mathbf{0 . 5 5 5}$ & $0.695^{* *}$ \\
\hline & $\mathbf{G}$ & -0.038 & -0.755 & 1.023 & -0.019 & $\mathbf{0 . 5 0 4}$ & $0.715^{* *}$ \\
\hline
\end{tabular}

Table.4 Phenotypic and genotypic path path coefficients of single plant grain yield and yield contributing traits in Swarna x 166s RILsin Kharif 2019

\begin{tabular}{|l|c|c|c|c|c|c|c|}
\hline Trait & P/G & PH & TN & PTN & TGW & BM & $\begin{array}{c}\text { Correlation with } \\
\text { SPY }\end{array}$ \\
\hline PH & P & $\mathbf{0 . 1 3 8}$ & -0.020 & -0.018 & 0.004 & 0.049 & $0.152^{* *}$ \\
\hline & G & $\mathbf{- 0 . 0 7 4}$ & 0.128 & -0.077 & 0.005 & 0.313 & $0.296^{* *}$ \\
\hline TN & P & 0.138 & $\mathbf{- 0 . 0 2 0}$ & -0.018 & 0.004 & 0.049 & $0.693^{* *}$ \\
\hline & G & 0.009 & $\mathbf{- 1 . 0 7 0}$ & 1.062 & -0.029 & 0.381 & $0.352^{* *}$ \\
\hline PTN & P & -0.009 & 0.281 & $\mathbf{0 . 2 7 6}$ & -0.008 & 0.151 & $0.691^{* *}$ \\
\hline & G & 0.005 & -1.059 & $\mathbf{1 . 0 7 2}$ & -0.023 & 0.313 & $0.308^{* *}$ \\
\hline TGW & P & 0.010 & -0.050 & -0.038 & $\mathbf{0 . 0 5 4}$ & -0.030 & -0.054 \\
\hline & G & -0.002 & 0.198 & -0.156 & $\mathbf{0 . 1 5 9}$ & -0.137 & $0.062^{* *}$ \\
\hline BM & $\mathbf{P}$ & 0.030 & 0.202 & 0.187 & -0.007 & $\mathbf{0 . 2 2 3}$ & $0.635^{* *}$ \\
\hline & G & -0.036 & -0.633 & 0.521 & -0.034 & $\mathbf{0 . 6 4 3}$ & $0.462^{* *}$ \\
\hline
\end{tabular}

Table.5 Pooled Phenotypic and genotypic path coefficients of single plant grain yield and yield contributing traits in Swarna x 166s RILs over three seasons

\begin{tabular}{|c|c|c|c|c|c|c|c|}
\hline Trait & $P / G$ & PH & TN & PTN & TGW & BM & $\begin{array}{l}\text { Correlation } \\
\text { with SPY }\end{array}$ \\
\hline \multirow[t]{2}{*}{ PH } & $\mathrm{P}$ & 0.186 & 0.023 & -0.067 & 0.000 & 0.067 & $0.21 * *$ \\
\hline & G & 0.235 & 0.386 & -0.438 & 0.000 & 0.103 & $0.287 * *$ \\
\hline \multirow[t]{2}{*}{ TN } & $\mathrm{P}$ & -0.021 & -0.205 & 0.497 & -0.005 & 0.097 & $0.364 * *$ \\
\hline & G & -0.057 & -1.585 & 1.592 & 0.005 & 0.079 & 0.034 \\
\hline \multirow[t]{2}{*}{ PTN } & $\mathrm{P}$ & -0.024 & -0.195 & 0.521 & -0.004 & 0.087 & $0.385^{* *}$ \\
\hline & G & -0.063 & -1.551 & 1.627 & 0.004 & 0.068 & 0.084 \\
\hline \multirow[t]{2}{*}{ TGW } & $\mathrm{P}$ & 0.002 & 0.034 & -0.079 & 0.028 & 0.000 & -0.016 \\
\hline & G & 0.000 & 0.345 & -0.327 & -0.021 & 0.005 & 0.001 \\
\hline \multirow[t]{2}{*}{ BM } & $\mathrm{P}$ & 0.052 & -0.082 & 0.186 & 0.000 & 0.243 & $0.399 * *$ \\
\hline & G & 0.081 & -0.420 & 0.370 & 0.000 & 0.298 & $0.329 * *$ \\
\hline & & esidua & $\begin{array}{l}\text { ect }=0 \text {. } \\
\text { BOLD v }\end{array}$ & Ph & $\begin{array}{l}\text { pic res } \\
\text { effects }\end{array}$ & I effect & 3806 \\
\hline
\end{tabular}




\section{Direct effects on grain yield}

When considering the direct effects of traits across the environments; in Rabi 2017/18 among the traits studied, except total tiller number per plant and 1000-grain weight the other traits showed positive association with single plant grain yield at both phenotypic and genotypic levels. Productive tiller number per plant had the highest direct effect on single plant grain yield followed by plant height and biomass weight per plant. Productive tiller number per plant and total tiller number per plant had positive and significant correlation with single plant grain yield.

In Rabi 2018/19all the traits had significant positive correlation with single plant grain yield. Total tiller number per plant had negative direct effect at both phenotypic and genotypic levels and at genotypic level only plant height showed negative direct effect. All the other direct effects were positive. Productive tiller number per plant had the highest direct effect on single plant grain yield followed by biomass weight per plant and 1000-grain weight at both levels.

In Kharif2019, except negative nonsignificant correlation of 1000-grain weight at phenotypic level all the other traits were correlated positively with single plant grain yield. Total tiller number per plant had negative direct effect at both phenotypic and genotypic levels and at genotypic level only plant height showed negative direct effect. All the other direct effects were positive. Productive tiller number per plant had the highest direct effect on single plant grain yield followed by biomass weight per plant and 1000-grain weight at both levels. The pattern of direct effects in Kharif 2019 was same as the pattern showed in Rabi 2018/19.

The pooled data of all the three environments showed that, plant height and biomass weight per plant had significant correlation with single plant grain yield at both genotypic and phenotypic levels. Total tiller number per plant and productive tiller number per plant had significant association with single plant grain yield at phenotypic level only. The direct effects of total tiller number per plant at both levels and 1000-grain weight at genotypic level had negative direct effects. Productive tiller number per plant had the highest positive direct effect followed by biomass weight per plant and plant height at both phenotypic and genotypic levels and indicated their importance and relative contribution to increase the grain yield per plant in rice in a selection programme. Similar findings were reported by Meena et al., 2020; Golam et al., 2015;Rahman et al., 2014, Jadhav et al.,2018; Krantikumar et al., 2016; Naseer et al., 2015; Nagaraju et al., 2013, for plant height;Meena et al., 2020; Akter et al., 2019;Kiranmayee et al., 2018; Rathod et al.,2 016; Golam et al., 2015; Kishore et al., 2015; Rahman et al., 2014;Hasan et al., 2013 for productive tiller number per plant; Jadhav et al., 2018; Ravi et al., 2014 for negative direct effect of total tillers per plant. Patel et al., 2014 reported that straw yield per plant had the highest positive direct effect on grain yield.

\section{Indirect effects on grain yield}

When considering the indirect effects of the component traits on single plant grain yield, in Rabi 2017/18 total tiller number per plant and the productive tiller number per plant had significant association with single plant grain yield at both phenotypic and genotypic levels. The positive effect of tiller number per plant with the single plant grain yield was nullified by the direct effect and among the traits studied productive tiller number per plant had indirect effect to increase the single plant grain yield. The positive effect of productive tiller number per plant with the single plant 
grain yield was mainly due to the direct effect itself. The positive relationships of plant height and biomass per plant with single plant grain yield mainly due to the direct effects of the traits.

In Rabi 2018/19 all the traits studied showed positive correlation with single plant grain yield at both phenotypic and genotypic levels. Plant height showed positive effect with single plant grain yield mainly due to the indirect effect of biomass weight per plant. The positive effect of total tiller number per plant on single plant grain yield was nullified by the direct effect and supported by the indirect effect of productive tiller number per plant. The positive effect of productive tiller number per plant on single plant grain yield mainly due to the direct effect of the trait and the indirect effect of biomass weight per plant. The positive effect of 1000-grain weight was mainly due to it's direct effect. The positive effect of biomass weight per plant on single plant grain yield was due to the direct effect of the trait and the indirect effect productive tiller number per plant, revealing the close relation between the traits of biomass weight per plant and productive tiller number per plant.

In Kharif 2019 except the phenotypic effect of 1000-grain weight all the other traits had significant positive effect on single plant grain yield. The direct effect of plant height at phenotypic level caused the improvement of the character and, when direct effect at genotypic level nullified, it the indirect effect of biomass weight per plant affected positively. The direct effect of total tiller number per plant nullified the positive effect on single plant grain yield. Phenotypic effect of plant height and genotypic effect of productive tiller per plant and biomass weight per plant indirectly affected to increase the character. The positive correlation of productive tiller number per plant with single plant grain yield was due to the direct effect of the trait and indirect effect of the biomass weight per plant. The 1000-grain weight was mainly increased by the direct effect and the indirect effect of total tiller number at genotypic level. The positive correlation of biomass weight per plant with single plant grain yield was mainly due to the direct effect of biomass weight per plant and the indirect effect of total tiller number per plant.

The pooled path analysis for three season data recorded that; plant height and biomass weight per plant had positive effect on single plant grain yield at both phenotypic and genotypic levels. Total tiller number per plant and productive tiller number per plant affected significantly at phenotypic level. The positive effect of plant height on single plant grain yield mainly due to the direct effect of the trait and indirect effects of total tiller number plant and biomass weight per plant. Total tiller number per plant had positive effect on single plant grain yield mainly due to productive tiller number per plant, but its direct effect was negative. Productive tiller number per plant had positive effects on single plant grain yield mainly due to the direct effect of the character and indirect effect of biomass weight per plant. Biomass weight per plant had the highest positive correlation on single plant grain yield mainly due to its direct effect and indirect effect of productive tiller number per plant.

The genotypic residual effect and the phenotypic residual effects of the present study were 0.75124 and 0.73806 respectively indicating that these characters alone contributed for variability in grain yield by 25 percent genotypically and 27 percent phenotypically. This gives an impression that some other major characters also contribute to the variability of grain yield. This residual effect towards yield may be due to different reasons, such as other main characters which 
are not included in the study, sampling errors or environmental factors etc. Therefore phenotyping and analyzing more number of characters could be preferred based on traits mainly contributing to the variance of grain yield.

Ratna et al., 2015, reported residual effect of 0.170 indicating about $83 \%$ of the variability in grain yield was contributed by the eleven characters studied viz., plant height, days to $50 \%$ flowering, days to maturity, number of effective tillers/plant, number of ineffective tillers/plant, number of total tillers/plant, panicle length, number of filled spikelet/panicle, number of unfilled spikelets/panicle, number of total spikelets/panicle, weight of 1000-seeds in path analysis. In a study of path analysis Akter et al., 2019 reported residual effect of 0.017 , by using eight yield contributing traits viz., days to maturity, number of effective tiller per square meter, plant height, panicle length, number of spikelets per panicle, spikelet fertility, panicle weight and 1000grain weight. This indicated that about 98 percent of variability in grain yield might be contributed by these characters.

In conclusion, the path analysis revealed that that the traits productive tiller number, biomass weight per plant and plant height had direct effect with single plant grain yield at both phenotypic and genotypic levels. Total tiller number at both levels and 1000-grain weight at genotypic level had negative direct effect on single plant grain yield. Productive tiller number per plant had a close relationship with the biomass yield per plant to enhance the trait single plant grain yield. Therefore, this investigation reveals the importance of simultaneous selection for productive tiller number, biomass weight per plant and plant height to increase the single plant yield in rice crop.

\section{Acknowledgements}

This research was carried out as a part of the $\mathrm{PhD}$ research work entitled "Stability analysis of wild introgression lines in rice using AMMI and GGE biplot analysis" of the first author at College of Agriculture, PJTSAU and Indian Institute of Rice Research, Hyderabad, India. Financial support and scholarship for $\mathrm{PhD}$ studies to the first author from Sri Lanka Council for Agricultural Research Policy, Sri Lanka is greatly acknowledged. The authors are highly grateful to the Director and funding from project ABR/CI/BT/11, ICAR-IIRR for providing all the necessary facilities.

\section{References}

Akter, A., Hasan, M.J., Latif, M.A., Kulsum, M.U., Biswas, P.L., Rahman, M.H., Majumder, R.R., Lipi, L.F., Quddus, M,R., Akter, F and Ara, A. 2019. Genetic Variability, Heritability, Correlation and path coefficient studies for yield and yield components of some promising rice hybrids.Bangladesh Rice Journal.23 (2): 27-34.

Brar, D.S and Singh, K. 2011. Rice. In: C. Kole (ed.) - Wild crop relatives: genomics and breeding resources, Springer, Berlin. 321-365.

Calingacion, M., Laborte, A., Nelson. A., Resurreccion, A., Concepcion, J. C., Daygon, V. D., Mumm, R., Reinke, R., Dipti, S., Bassinell, P. Z., Manful, J., Sophany, S., Lara, K. C., Bao, J., Xie, L., Loaiza, K., El-hissewy, A., Gayin, J., Sharma, N., Rajeswari, S., Manonmani, S., Rani, N.S., Kota, S., Indrasari, S.D., Habibi, F., Hosseini, M., Tavasoli, F., Suzuki, K., Umemoto, T., Boualaphanh, C., Lee, H.H., Hung, Y.P., Ramli, A., Aung, P.P., Ahmad, R., Wattoo, J I., Bandonill, E., Romero, M., Brites, C.M., Hafeel, R., Lur, H.S., Cheaupun, K., Jongdee, S., Blanco, P., 
Bryant, R., Lang. N. T., Hall, R. D and Fitzgerald, M.2014. Diversity of Global Rice Markets and the Science Required for Consumer-Targeted Rice Breeding. PLOS ONE.9 (1).

Christopher, O.A and A. Y. Sangodoin. 2011. Evapo-transpiration, soil and water quality implications on upland rice production. Asian Journal of Crop Science.3:169-178.

Dewey, J.R and Lu, K.H. 1959. Correlation and path coefficient analysis of components of crested wheatgrass seed production. Agronomy Journal.51:515518.

FAO, 2016.The state of food and agriculture.Food and Agriculture Organization of the United Nations, Rome.

Golam, S., Md. Harun-Ur-R, Shahanaz, P and Md. Sarowar, H. 2015.Correlation and Genotypes (Oryza sativa L.).Advances in Bioresearch. 6 (4):40-47.

Haritha, G., Sudhakar, T., Chandra, D., Ram, T., Divya, B and Sarla, N. 2016.Informative ISSR Markers Help Identify Genetically Distinct Accessions of Oryzarufipogonin Yield Improvement.Rice Science.23 (5):225-241.

Hasan, M.J., Kulsum, M.U., Akter, A., Masuduzzaman, A.S.M and Ramesha, M.S. 2013. Genetic variability and character association for agronomic traits in hybrid rice (Oryza Sativa L). Bangladesh Journal of Plant Breeding andGenetics. 24 (1): 45-51.

Jadhav, S., Balakrishnan, D., Gouri Shankar V., Beerelli, K., Chandu, $\mathrm{G}$ and Neelamraju, S. 2018. Correlation and path coefficient analysis using a set of diverse genotypes of Oryza spp. Journal of Rice Research.11: 2.

Kiranmayee, B., Raju, C.D., KempaRaju, K.B and Balaram, M. 2018. A study on correlation and path coefficient analysis for yield and yield contributing traits in maintainer (B lines) lines of hybrid rice (Oryza sativa L.). International Journal of Current Microbiology and Applied Sciences.7 (6): 2918-2929.

Kishore, N.S., Srinivas, T., Nagabhushanam, U., Pallavi, M and Sameera, S.K. 2015. Genetic variability, correlation and path analysis for yield and yield components in promising rice (Oryza sativa L.) genotypes. SAARC Journal of Agriculture. 13 (1):99-108

Krantikumar, H.P., Lekha Rani, C., Roy, S., Vijayaraghava, $\mathrm{K}$ and Jayalekshmy, V.G. 2016.Path analysis in rainfed upland rice (Oryzasativa.L) under natural stress.International Journal of Scientific Research.5 (5):237-239.

Meena, D., Kumar, M., Sandhya, N., Koli, R., Tak, Y andMeena, A.K. 2020. Assessment of Correlation and Path coefficient analysis for yield and it's attributing traits in rice (Oryzasativa L.) genotypes. International Journal of Current Microbiology and Applied Sciences.9 (7): 3845-3851.

Nagaraju, C., Sekhar, M.R., Reddy, K.H and Sudhakar, P. 2013. Correlation between traits and path analysis coefficient for grain yield and other components in rice (Oryza sativa L.) genotypes.International Journal of Applied Biology and Pharmaceutical Technology.4 (3): 137-142.

Naseer, S., Kashif, M., Ahmad, H.M. Iqbal, M.S and Qurban Ali, Q. 2015.Estimation of genetic association among yield contributing traits in aromatic and non-aromatic rice (Oryza sativa L) cultivars.Life Science Journal.12 (4s):68-73.

Patel, J.R., Saiyad, M.R., Prajapati, K.N., Patel, R.A and Bhavani, R.T. 2014.Genetic variability and character association studies in rain-fed upland rice (Oryza sativa L.). Electronic 
Journal of Plant Breeding.5 (3):531537.

Pimsaen, W., Jogloy, S., Suriharn, B., Kesmala, T., Pensuk, V and Patanothai, A. 2010.Genotype by environment (GXE) interactions for yield components of Jerusalem artichoke (Helianthus tuberoses L.).Asian Journal of Plant Sciences.9:11-19.

Purugganan, M. D. 2014. An evolutionary genomic tale of two rice species. Nature genetics, 46:931-932.

Rahman, M. A., Hossain, M. S., Chowdhury, I.F., Matin, M.A and Mehraj, H. 2014. Variability study of advanced fine rice with correlation, path co-efficient analysis of yield and yield contributing characters.International journal of Applied Science and Biotechnology.2 (3):364-370.

Ram, T., Majumder, N.D and Mishra, B. 2010.Jarava: A new high yielding and pest-resistant rice variety for coastal saline areas. International Rice Research Notes. 34:1-4.

Ram, T., Majumder, N.D., Krishnaveni, D and Ansari, M.M. 2007.Rice variety Dhanrasi, an example of improving yield potential and disease resistance by introgressing gene (s) from wild species (Oryzarufipogon).Current

Science.92:987-992.

Rathod, R., Pulagam, M.B., Rao, S., Usharani, G., RavindraBabu,V. and Bharathi, M. 2016. Correlation and path coefficient analysis for yield, yield attributing and nutritional traits in rice
(Oryza sativa L.). Progressive Research - An International Journal.11: 23782381

Ratna, M., Begum, S., Husna, A., Dey, S.R and Hossain, M.S. 2015. Correlation and path coefficients analysesin basmati rice.Bangladesh Journal of Agricultural Research.40 (1):153-161.

Ravi, K., Suresh, B.G., Lavanya, G.R., Satish, K.R., Sandhya and Bandana, D.L. 2014. Genetic variability and character association amongbiometrical traits in $\mathrm{F}_{3}$ generation of some rice crosses.International Journal of Food, Agriculture and Veterinary Sciences. 4 (1): 155-159.

Roy, S.C and Shil, P. 2020. Assessment of Genetic Heritability in Rice Breeding Lines Based on Morphological Traits and Caryopsis Ultrastructure. Scientific Reports.10:7830.

Shakiba, E and Eizenga, G.C. 2014.Unraveling the secrets of rice wild species.In W. Yanand J, Bao (eds.). Rice germplasm, genetics and improvement.1-58.

Sreedhar, S., Reddy T.D and Ramesha, M.S. 2011. Genotype x environment interaction and stability for yield and its components in hybrid rice cultivars (Oryza sativa L.). International Journal of Plant Breeding and Genetics.5:194208.

Wright, S. 1921. Correlation and causation.Journal of Agricultural Research. 20: 257-287.

\section{How to cite this article:}

De Silva, N. P. S., V. G. Shankar, D. Balakrishnan, B. Kavitha, Y. V. Rao, P. Prashanthi, N. Sarla, SNCVL. Pushpavalli and Srinivasa Chary, D. 2021. Path Coefficient Analysis using Rils of Oryza nivara in Swarna Background. Int.J.Curr.Microbiol.App.Sci. 10 (02): 86-94. doi: https://doi.org/10.20546/ijcmas.2021.1002.010 